\title{
Preparation of a Concentrated Coal Water Slurry Dispersant Incorporating Sulfomethylated Alkali Lignin as a Raw Material
}

\author{
Xiao-Mei Chen \\ College of Environment \& Resources, Fuzhou University, \\ Fuzhou, Fujian, China
}

\begin{abstract}
Dispersants in coal water slurry have received considerable attention over the years with regards to their use in enhancing the properties of CWS. This paper focuses on the preparation of the low-cost, high-performance CWS dispersant. The novel concentrated coal water slurry dispersant was prepared by reacting the sulfomethylated alkali lignin with sulphonated acetone-formaldehyde polycondensate, and the effect of various factors on the dispersion ability was investigated. The results showed that when the $\mathrm{H}_{2} \mathrm{O}_{2}$ dosage was $5 \mathrm{~g}$, when the molar ratio of $\mathrm{CH}_{2} \mathrm{O}$ to $\mathrm{Na}_{2} \mathrm{SO}_{3}$ was 3.4 , and when the $\mathrm{Na}_{2} \mathrm{SO}_{3}$ dosage was $40 \%$, the apparent viscosity of CWS could reach 1074 mPa•s.
\end{abstract}

Index Terms - coal water slurry, dispersant, lignin, coal.

\section{INTRODUCTION}

Coal water slurry (CWS) technique is an important reform for overcoming the disadvantages of the traditional industrial application of coal, e.g., much clinker, serious pollution, etc. The use of coal-water slurry in combustion requires highdensity slurries consistent with low viscosity, good stability, and relatively long-time storage capabilities ${ }^{[1]}$. However, during the attainment of coal-water slurry of high-coal concentration, the viscosity of the slurry increases with every increase in the particle-particle interaction, thereby leading to severe adverse effects on the storage as well as on the transportation properties of the slurry. Since a significant region of the coal is hydrophobic, the interparticle association can be controlled by masking the hydrophobic sites of the coal or by rendering the coal surface with sufficient dispersant such that coal-water interaction will be promoted instead of coalcoal interaction. ${ }^{[2]}$ Thus, the dispersant plays an important role in the preparation of concentrated CWS systems.

Generally, the CWS dispersants belong to the anionic and the nonionic surfactants. This study put special stress on the anionic dispersant. Many previous papers have described the various types of anionic dispersants used to obtain CWS with a low viscosity and a high solids fraction [3]. Sodium naphthalene-sulfonate formaldehyde condensate (NSF), as the representative anionic dispersants, is often studied for the preparation of CWS. In general, the anionic dispersants contain various hydrophilic and hydrophobic groups. NSF contains two

\author{
Ming-Hua Liu*, Yi-Fan Liu \\ College of Environment \& Resources, Fuzhou University, \\ Fuzhou, Fujian, China \\ mhliu2000@fzu.edu.cn
}

or more fused aromatic rings, sulfonic groups, and alkyl group, so a significant amount of NSF with both polar and nonpolar regions can be adsorbed quickly onto the coal particle surface through hydrophobic interaction ${ }^{[4]}$. Then, the free water fills in the void gap between coal particles, which guarantees lubricity and mobility between the particles ${ }^{[5]}$. However, the shortage of NSF raw material leads to the product's high cost, and for this reason many researchers have focused on the newly developed low-cost dispersants.

Some studies have shown that NSF structures with aromatic rings, sulfonic groups, and so on, have a major impact on the high-efficiency dispersant for CWS. many researchers have focused their attentions on the lignin that belongs to the aromatic macromolecular compound existing in plants. Most of lignin is produced as a byproduct of the pulp and paper industry ${ }^{[6]}$. In addition, the lignin contains other groups, such as hydroxy, phenol hydroxy, carboxyl, and methoxy groups, that meet the requirements for the additives with both polar and nonpolar regions ${ }^{[7]}$. However, the molecular weight of alkali lignin obtained from the sulphate pulping process is very low, so the unmodified alkali lignin is not acceptable for preparing CWS with high oxygen and high inherent moisture contents. Thus, considerable attention has been focused on the preparation of modified lignin-based dispersants for use in CWS. Wu investigated the oxidation and sulfomethylation of alkali-extracted lignin from corn stalk, and the literature reported that the sulfomethylation products exhibited good dispersibility and potential for use as a dye dispersant ${ }^{[4]}$. However, the additives mentioned above can only be used to prepare CWS made up of the coals with low oxygen and low inherent moisture contents, and the additional dosage of the additives was large. Additionally, the coals with low oxygen and low inherent moisture contents are expensive and unabundant in China, whereas the low-rank bituminous coals and lignitic coals with high oxygen and high inherent moisture contents are commonly used in China in the preparation of $\mathrm{CWS}^{[8]}$. Aiming to solve the problem, Zhou mentioned a novel synthetic dispersant obtained from black liquor which the black liquor was modified via grafting and a methylolation reaction. Shenhua coal is abundant in modern-day China ${ }^{[9]}$. However, the maximum solid content of CWS prepared from Shenhua 
coal with the dispersant obtained from the modified black liquor only reached $60.5 \%$. Consequently, preparing a new dispersant in order to increase the maximum solid content of CWS prepared from Shenhua coal is crucial.

Presently, it has been of urgent necessity to develop efficient, low-cost dispersants for the preparation of highconcentration CWS with relatively low viscosity and nonsettling and free-flowing properties using low-ranking bituminous coals, i.e., Shenhua coal. In this paper, a low-cost, high-performance CWS dispersant was prepared with sulphonated acetone-formaldehyde polycondensate using sulphonated alkali lignin as a raw material. In this way, the molecular weight of the alkali lignin was improved and the lipophilic groups and hydrophilic groups were engrafted into the structure of the alkali lignin. While the hydrophobicity of the coal surface increased via the lipophilic groups, this came with an increase in the concentration of CWS. The slurry ability of the CWS prepared from Shenhua coal was thus improved.

\section{EXPERIMENTAL}

\section{A. Materials}

The alkali lignin from the masson pine kraft pulping process was obtained from the Nanpin Paper Group Co., Ltd., Fujian, China. The reagents, i.e., acetone, sodium sulfite, formaldehyde solution (37\%), sulfuric acid solution (20\%), hydrogen peroxide, etc., were chemically pure. The commercial naphthalene sulfonate-formaldehyde condensate, denoted as NSF, was provided by Fude chemical Co., Ltd, Wuhan province, China.

The Shenhua coal were selected as the raw materials for the coal water slurry. The elementals and proximate analyses of the coal are summarized in Table 1.

\section{B. Instruments}

The apparatuses used included a MA100 moisture rapid determination instrument (Sartorius Co, Germany), a Nicolet Avatar 360 FTIR spectrometer (Perkiin-Emler Co, United States), an Agilent 1100 gel permeation chromatography (GPC) and an NXS-4C coal water slurry viscometer (Chengdu Instrument Factory, Sichuan, China).

\section{Preparation of $A L B$}

Alkali lignin (AL) was dissolved at 50 to $80^{\circ} \mathrm{C}$. Next, the sulfuric acid solution (20\%) was added dropwise into the solution in order to adjust the solution $\mathrm{pH}$. Then, hydrogen peroxide was fed into the reactor for oxidation. After 1.0 hours, formaldehyde was added in the reactor flask at a definite reaction temperature for a certain reaction time. Subsequently, sodium sulfite was added. After a certain reaction time, the sulfomethylated alkali lignin (SAL) was obtained. Then, water, sodium hydroxide, and acetone were added successively to another reactor. After $30 \mathrm{~min}$, the sodium sulfite was added into the above mixture. $60 \mathrm{~min}$ later, $\mathrm{SAL}$ was fed into the reactor while the formaldehyde was slowly added at $90{ }^{\circ} \mathrm{C}$. After 3 hours, the CWS dispersant, i.e., an alkali lignin-based (ALB) dispersant, was thus obtained.
TABLE I. Elemental AND Proximate ANALySES OF Shenhua coA

\begin{tabular}{|c|c|c|c|c|c|c|}
\hline Coals & $\begin{array}{c}\text { Inherent } \\
\text { moisture } \\
(\%)\end{array}$ & $\begin{array}{c}\text { Ash } \\
(\%)\end{array}$ & $\begin{array}{c}\text { Volatile } \\
\text { matter } \\
(\%)\end{array}$ & $\begin{array}{c}\text { Carbon } \\
(\%)\end{array}$ & $\begin{array}{c}\text { Hydrogen } \\
(\%)\end{array}$ & $\begin{array}{c}\text { Sulfur } \\
(\%)\end{array}$ \\
\hline Shenhua & 4.06 & 12.25 & 31.96 & 55.79 & 4.33 & 0.35 \\
\hline
\end{tabular}

D. Characterizations of $A L B$

The sulfonic group content of the samples was determined using an automatic potentiometric titrator. The weight-average molecular weights (Mw) of the AL and ALB were determined by GPC. Furthermore, the Fourier transform infrared spectrometry of the Auto system XL/i-series/Spectrum 2000PE was used for infrared spectrum analysis.

\section{E. The Slurrying Ability of CWS Measurements}

The apparent viscosity of the CWS was determined with a CWS viscometer. All experiments were conducted at the room temperature of $25^{\circ} \mathrm{C}$.

\section{RESULTS AND DISCUSSION}

\section{A. Oxidation of alkali lignin}

$\mathrm{H}_{2} \mathrm{O}_{2}$ oxidation is beneficial to improving the reactivity of $\mathrm{AL}$. Wu mentioned that the oxidation degree of AL has a significant effect on the sulfomethylation of $\mathrm{AL}^{[4]}$. In this paper, the impacts of the $\mathrm{H}_{2} \mathrm{O}_{2}$ dosage and $\mathrm{pH}$ on the modification of $\mathrm{AL}$ were investigated. The raw materials ratio in the reaction solution was kept constant and the $\mathrm{pH}$ of the reaction solution was adjusted to $3 \sim 13$. The $\mathrm{H}_{2} \mathrm{O}_{2}$ dosage was changed to determine the dispersing abilities. The results are illustrated in Fig. 1.

As Fig. 1 shows, the apparent viscosity of the CWS decreased with the increase in the $\mathrm{H}_{2} \mathrm{O}_{2}$ dosage when the solution $\mathrm{pH}$ ranged from 3 to 5 , indicating that the acid surrounding favored the oxidation of AL. However, the effects of $\mathrm{H}_{2} \mathrm{O}_{2}$ dosage on the apparent viscosity of the CWS were not evident in the alkaline surrounding, as seen in Fig. 1. A possible reason for these results was that the acid surrounding aroused the freed hydroxide radical from the $\mathrm{H}_{2} \mathrm{O}_{2}$, leading to the cleavage of ether linkages in the AL and thus forming the phenolic hydroxyl group. The increasing content of the phenolic hygroxyl was favorable for the sulfomethylation reaction.

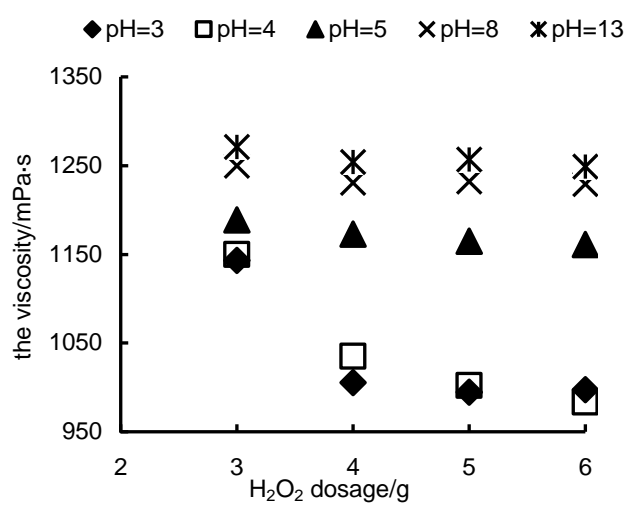

Fig. 1. Effects of $\mathrm{H}_{2} \mathrm{O}_{2}$ dosage on the apparent viscosity of CWS 
On the other hand, the weakened oxidizability of $\mathrm{H}_{2} \mathrm{O}_{2}$ in the alkaline surrounding resulted in the reduction of phenolic hydroxyl. Next, the active sites of the sulfomethylation reactions decreased. This could be attributed to the fact that the basic surrounding was beneficial to engrafting the sulphonated acetone to the AL by condensation, which would increase the molecular weight of the ALB. This was why the apparent viscosity of the CWS with ALB synthetized at $\mathrm{pH}=13$ was lower than that at $\mathrm{pH}=8$.

\section{B. Effects of $\mathrm{Na}_{2} \mathrm{SO}_{3}$ Dosage and Molar Ratio of $\mathrm{HCHO}$ to $\mathrm{Na}_{2} \mathrm{SO}_{3}$}

The molecular weight and sulfonic group content are two key factors affecting the dispersity of the dispersant for use in $\mathrm{CWS}^{[1]}$. In this study, the molecular weight and sulfonic group content of ALB were found to be greatly influenced by the $\mathrm{Na}_{2} \mathrm{SO}_{3}$ dosage and formaldehyde dosage.Formaldehyde was reacted with $\mathrm{Na}_{2} \mathrm{SO}_{3}$ to produce $\mathrm{HOCH}_{2} \mathrm{SO}_{3}$ which was engrafted in the ortho-position of phenolic hydroxyl groups by sulfomethylation reaction ${ }^{[10]}$. The mass ratios of the total reaction materials, aside from the sulfonating agent $\left(\mathrm{Na}_{2} \mathrm{SO}_{3}\right)$ and formaldehyde, were kept constant, and the $\mathrm{Na}_{2} \mathrm{SO}_{3}$ dosage was adjusted to obtain ALB products with different sulfonic group contents and molecular weights, as shown in Table 2.

ALB with different sulfonic group contents and molecular weights were used to prepare CWS. From Fig. 2, when the mass ratios of the $\mathrm{Na}_{2} \mathrm{SO}_{3}$ accounting for alkali lignin increased from $30 \%$ to $50 \%$, the apparent viscosity of the CWS decreased. In the synthesis process, the reaction between the sodium sulfite $\left(\mathrm{Na}_{2} \mathrm{SO}_{3}\right)$ and the formaldehyde $\left(\mathrm{CH}_{2} \mathrm{O}\right)$ generated the reactive intermediate $\left(\mathrm{NaSO}_{3} \cdot \mathrm{CH}_{2} \mathrm{OH}\right)$, and then the $\mathrm{HOCH}_{2} \mathrm{SO}_{3}$ was engrafted by sulfomethylation in the ortho-position of phenolic hydroxyl groups in the lignin molecules. The increasing $\mathrm{Na}_{2} \mathrm{SO}_{3}$ dosage in the total reaction materials generated more reactive $\mathrm{NaSO}_{3} \cdot \mathrm{CH}_{2} \mathrm{OH}$ intermediate, and the reactive $\mathrm{HOCH}_{2} \mathrm{SO}_{3}$ occupied a more active site in the lignin molecules, which increased the sulfonic group contents of the lignin molecules in the ALB ${ }^{[9]}$.

TABLE II. EFFECT OF $\mathrm{NA}_{2} \mathrm{SO}_{3}$ DOSAGE AND RATIO OF $\mathrm{CH}_{2} \mathrm{O}$ TO $\mathrm{NA}_{2} \mathrm{SO}_{3}$ ON THE PROPERTIES OF ALB

\begin{tabular}{|c|c|c|c|}
\hline $\begin{array}{c}\mathrm{W}\left(\mathrm{Na}_{2} \mathrm{SO}_{3}\right) / \\
W(\text { lignin })(\%)\end{array}$ & $\begin{array}{l}\text { Ratio of } \\
\mathrm{CH}_{2} \mathrm{O} \text { to } \\
\mathrm{Na}_{2} \mathrm{SO}_{3} \\
\end{array}$ & $\begin{array}{c}\text { Sulfonic group } \\
\text { content }\left(\text { mmol } \bullet^{-1}\right)\end{array}$ & $M w$ \\
\hline 0 & - & - & 3100 \\
\hline \multirow{3}{*}{$30 \%$} & 2.7 & 1.11 & 8409 \\
\hline & 3.4 & 1.20 & 10130 \\
\hline & 3.6 & 1.23 & 12009 \\
\hline \multirow{3}{*}{$40 \%$} & 2.7 & 1.73 & 7140 \\
\hline & 3.4 & 2.25 & 7290 \\
\hline & 3.6 & 2.32 & 7580 \\
\hline \multirow{3}{*}{$50 \%$} & 2.7 & 2.31 & 6569 \\
\hline & 3.4 & 2.29 & 6563 \\
\hline & 3.6 & 2.33 & 6567 \\
\hline
\end{tabular}

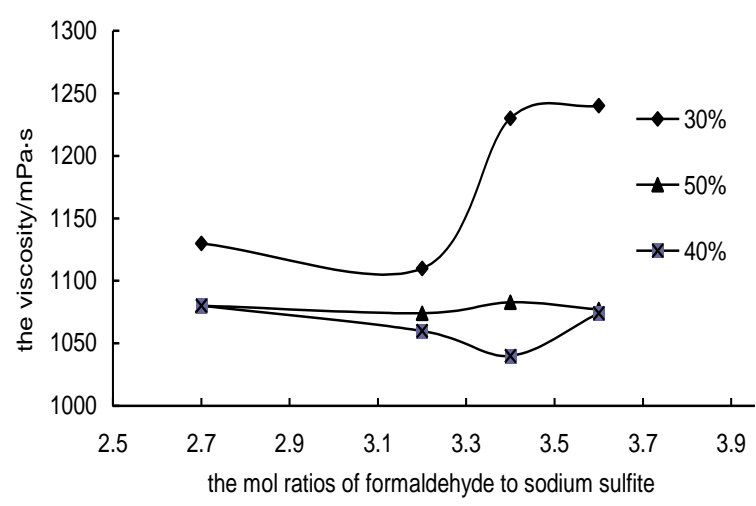

Fig. 2. Effect of the $\mathrm{Na}_{2} \mathrm{SO}_{3}$ dosage and formaldehyde dosage on the apparent viscosity

\section{FTIR Spectroscopy}

The FTIR spectra of unmodified (AL) and modified lignin (ALB) are shown in Fig. 3. The FTIR spectra of AL were characterized by a broad aromatic ring at $3452 \mathrm{~cm}^{-1}$ and at $2368 \mathrm{~cm}^{-1}$, typical of methoxyl groups.

As showed in Fig. 3, the spectrum of ALB exhibited a strong absorbance in the bands at $1215 \mathrm{~m}^{-1}$ and $1045 \mathrm{~cm}^{-1}$, denoting a sulfonic group, while the spectrum of AL had no absorbance in the above bands. The absorbance at $2945 \mathrm{~cm}^{-1}$ was stronger, denoting an alkyl group ${ }^{[11]}$. This indicated that the sulfomethylation reaction increased the alkyl group and the contents of the sulfonic and carbonyl groups. Thus, the watersoluble lignin could be adsorbed onto the coal surface, and the hydrophilic groups provided hydrophilicity and electronegativity to the coal particles. The hydrophilic hydration layer on the coal surface and the electrostatic repelling force between coal particles made the coal particles disperse in water ${ }^{[13]}$. Compared to the spectrum of AL, the spectrum of ALB in the bands at $1633 \mathrm{~cm}^{-1}$ and $1516 \mathrm{~cm}^{-1}$ denoting the aromatic group emerged strongly. This showed that by oxidating the AL, the content of the aromatic group was increased.Equations

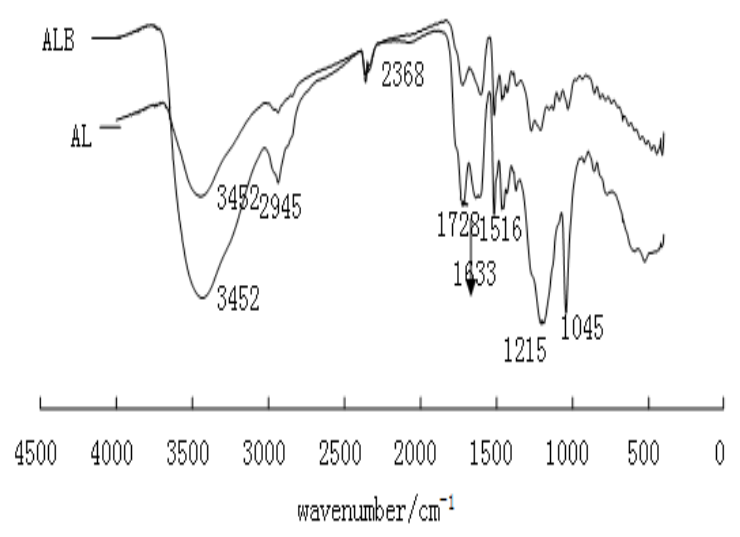

Fig. 3. FTIR spectra of AL and ALB 


\section{CONCLUSION}

On the basis of the investigation, if Alkali lignin is modified using an oxidant, a sulfonating agent, and a condensating agent, then the obtained product can be used to prepare a highly concentrated CWS of 63 wt.\% coal content with a dispersant dosage of $0.9 \%$ from Shenhua coal with apparent viscosities lower than $1200 \mathrm{mPa} \bullet \mathrm{s}$. The sulfonic group content and molecular weight of the ALB are greatly influenced by the sulfonating agent $\left(\mathrm{Na}_{2} \mathrm{SO}_{3}\right)$ dosage and the ratio of $\mathrm{Na}_{2} \mathrm{SO}_{3}$ to $\mathrm{CH}_{2} \mathrm{O}$ in the synthesis reaction. Increasing the sulfonating agent and formaldehyde dosage increases the sulfonic group content, but an excessive amount of sulfonating agent and formaldehyde dosage reduces the molecular weight of ALB. The ALB with a higher sulfonic group content and an appropriate molecular weight has better dispersing ability and static stability for use in the CWS.

\section{ACKNOWLEDGMENTS}

The authors express their sincere thanks to the Fujian Provincial Department of Science \& Technology for financial support through their sanction of a project from the Important Science and Technology Item of the University-Industry Cooperation, Fujian Province (No. 2010H6011). The authors also appreciate the financial support from the Fujian Provincial Economy and Trade Commission through their sanction of a project from the Special Construction of Public Support System of Enterprise Technology Innovation, Fujian Province.

\section{REFERENCES}

[1] Pawlik, M. (2005). "Polymeric dispersants for coal-water slurries," Colloids Surf. A 266, 82-90.
[2] Das, D., Dash, U., Nayak, A., and Misra, P. K. (2010). "Surface engineering of low rank Indian coals by starch-based additives for the formulation of concentrated coal water slurry," Energy Fuel 24, 1260-1268.

[3] Aktas, E. Z., and Woodburm, T. (1999). "Effect of addition of surface active agent on the viscosity of a high concentration slurry of a low-rank British coal in water," Fuel Processing Technology 62, 1-15.

[4] Wu, H., Chen, F., Feng, Q., and Yue, X. (2012). "Oxidation and sulfomethylation of alkali extracted lignin from corn stalk," BioResources 7(3), 2742-2751.

[5] Hao, A. M., Li, X. S., and Song, Y. W. (2001). "Effect on slurry ability of CWS about modified coal," Coal Convers. 24(3), $47 \mathrm{C} 5$.

[6] Yuan, T. Q., Sun, S. N., Xu, F., and Sun, R. C. (2011). "Isolation and physicochemical characterization of lignins from ultrasound irradiated fastgrowing poplar wood," BioResources 6 , 414-433.

[7] Zhen, F., Liu, Y. F., and Liu, M. H. (2012). "Study on high density dyeing and printing waste water applied to preparation of coal water slurry," Coal Engineering 2, 85-91.

[8] Zhang, R. Z., and Hu, K. M. (1988). "Preparation and combustion techniques of water and coal mixture," Coal Sci. Technol. 11, 11-5.

[9] Zhou, M., Kong, Q., Pan, B., Qiu, X., Yang, D., and Lou, H. (2010). "Evaluation of treated black liquor used as dispersant of concentrated coal-water slurry," Fuel 89 716-723.

[10] He, W., Tai, D., and Li, Z. (1994). "Effect of formaldehyde during alkaline sulfite pulping of wheat straw," Transactions of China Pulp and Paper 9, 1-7.

[11] Zhang, H. (2010)."Pop learning principle and application" Chemical Industry Press 23-24. 